\title{
Of ions and temperature: the complicated interplay of temperature, fluids, and electrolytes on myocardial function
}

\author{
Kees H Polderman
}

See related research by Rungatscher et al., http://ccforum.com/content/17/5/R245

\begin{abstract}
This article discusses the potential of levosimendan to treat calcium-induced myocardial dysfunction associated with deep hypothermia. Moderate hypothermia (30 to $34^{\circ} \mathrm{C}$ ) usually improves myocardial contractility and stabilizes heart rhythm, but deep hypothermia can cause severe myocardial dysfunction, which is mediated by intracellular calcium overload. In experimental studies, levosimendan appears effective in reversing this. Clinical studies are needed to confirm these findings and to determine whether levosimendan could also be used for accidental hypothermia and perhaps to mitigate diastolic dysfunction under moderate hypothermia.
\end{abstract}

Lowering core temperature has complex and divergent effects on the myocardium, stimulating or inhibiting contractility and heart rhythm through several different mechanisms. The effects vary with the depth of hypothermia and are influenced by volume status, heart rate (which itself is affected by hypothermia), endocrine factors, and (crucially) extracellular and intracellular electrolyte concentrations. In general, moderate hypothermia (30 to $34^{\circ} \mathrm{C}$ ) improves myocardial contractility whereas deep hypothermia $\left(<28^{\circ} \mathrm{C}\right)$ has the opposite effect. Under specific circumstances (presence of tachycardia, hypovolemia, or electrolyte disorders), moderate hypothermia can also cause myocardial dysfunction.

Electrolytes, particularly calcium, play a key role in maintaining myocardial contractility through mechanisms that are also temperature-dependent. In the previous issue of Critical Care, Rungatscher and colleagues

Correspondence: k.polderman@tip.nl

Department of Critical Care Medicine, University of Pittsburgh Medical Center, 3550 Terrace Street, 601A Scaife Hall, Pittsburgh, PA 15261, USA
[1] present the results of a study on a key issue affecting deep hypothermic circulatory arrest (DHCA): reversing calcium-mediated persistent myocardial dysfunction after rewarming from DHCA.

Moderate hypothermia ( 30 to $34^{\circ} \mathrm{C}$ ) increases intracellular $\mathrm{Ca}^{2+}$ transients in a dose-dependent fashion, thereby increasing myocardial contractility [2]. However, deep hypothermia $\left(<28^{\circ} \mathrm{C}\right)$ can lead to intracellular calcium overload, especially when hypothermia is maintained for more than 30 minutes [3-5]. Intracellular hypercalcemia is corrected only slowly during and after rewarming from deep hypothermia, often leading to persistent myocardial dysfunction [3-5]. In addition, deep hypothermia can induce calcium desensitization, which usually develops during rewarming after DHCA. Diastolic relaxation, in turn, is rate-limited by removal of $\mathrm{Ca}^{2+}$ from the cytoplasm and the rate of cross-bridge detachment [6].

These issues are further complicated by hypothermiainduced changes in excretion of calcium and other electrolyte levels as well as on electrolyte shifts and changes in intracellular $\mathrm{pH}$. Urinary electrolyte excretion can increase markedly during induction of hypothermia, and a pronounced intracellular shift of potassium, magnesium, phosphate, calcium, and (to a lesser extent) sodium will occur [7-9]. This intracellular shift is reversed when the patient is rewarmed $[7,8]$. All this can have profound effects on the myocardium; this applies in particular to hypocalcemia, which can cause myocardial dysfunction, hypotension, arrhythmias, and failure to respond to drugs that act through calcium-mediated mechanisms (norepinephrine, dopamine, digoxin, and so on). Deficiencies of magnesium, potassium, and phosphate can also induce myocardial dysfunction and arrhythmias [7]. Conversely, intracellular influx of magnesium can help stabilize cellular membranes, improve intracellular 
energy management, and mitigate effects of calcium overload (which can occur during deep hypothermia but also during ischemia) $[7,8]$. In addition, intracellular $\mathrm{pH}$ increases during hypothermia, potentially enhancing myocardial contractility by offsetting the calciumdesensitizing effect of hypothermia [10,11]. Intracellular $\mathrm{Na}^{+}$can also increase, leading to increased production of reactive oxygen species (ROS) in the mitochondria [12]. This may initially improve intracellular homeostasis through more effective intracellular signaling and energy management [13], but when the rise is excessive, ROS can severely damage intracellular structures $[7,13]$. However, in yet another twist, mild hypothermia itself mitigates excessive ROS production, countering the potentially dangerous nitric oxide synthase toxicity [7].

Thus, the effects of moderate hypothermia on electrolytes in general and on calcium in particular are convoluted, with numerous and often conflicting effects on myocardial tissue. However, with deep hypothermia, some myocardial dysfunction will almost invariably occur, which is mediated to a substantial degree by intracellular calcium overload.

Epinephrin is the drug most commonly used to treat refractory hypotension in this situation. Rungatscher and colleagues [1] compared epinephrine with the calcium sensitizer levosimendan to reverse myocardial dysfunction after rewarming from DHCA in a rat model. They report that levosimendan was significantly more effective in reversing systolic and diastolic myocardial dysfunction, independent of volume status. Levosimendan also improved ventricular relaxation, better preserved myocardial ATP content, and reduced plasma lactate concentrations [1].

The same authors previously reported that levosimendan has better inotropic and lusitropic effects than epinephrine during rewarming from DHCA [14]. Others have published similar findings, with positive inotropic effects of levosimendan irrespective of the temperature.

Given these experimental data, levosimendan appears to be a highly promising drug to improve myocardial function during and after deep hypothermia, with a number of theoretical advantages over the commonly used epinephrine. The drug now needs to be evaluated in clinical studies, not just in DHCA but also for accidental hypothermia, in which rewarming is often complicated by major hemodynamic problems.

Given the mechanisms outlined above, hemodynamic effects of hypothermia can be hard to predict. Moderate hypothermia (30 to $34^{\circ} \mathrm{C}$ ), induced under controlled conditions (euvolemia, preventing discomfort through sedation or other means, preserving normal serum electrolyte levels), will usually decrease heart rate, reduce risk of arrhythmias, markedly improve systolic function, and induce mild diastolic dysfunction. Under optimal conditions, the diastolic dysfunction has only minimal effects on myocardial performance, and the overall effect of cooling will be an improvement in myocardial contractility, increase in stroke volume, reduction in cardiac output $(\mathrm{CO})$ because of the decrease in heart rate, and stabilization or slight increase in blood pressure [7]. Indeed, several clinical studies have reported the successful use of hypothermia to treat refractory cardiac shock [7]. The balance between metabolic supply and demand improves because the decrease in metabolic demand (7\% to $10 \%$ per ${ }^{\circ} \mathrm{C}$ decrease in core temperature) exceeds the drop in $\mathrm{CO}$ [7].

However, under different conditions (especially the presence of tachycardia), myocardial contractility may be adversely affected even under moderate hypothermia [7]. Several studies have shown that increasing heart rate under normothermic conditions improves myocardial contractility and $\mathrm{CO}$ but that increasing heart rate under hypothermic conditions decreases myocardial contractility $[7,15]$. There is also a dichotomy in temperature effect on heart rhythm: membrane stabilization and decreased risk of arrhythmias with moderate hypothermia, increased risk of arrhythmias with deep hypothermia $\left(<28^{\circ} \mathrm{C}\right)[7]$.

The results of the study by Rungatscher and colleagues [1] for deep hypothermia suggest that levosimendan could potentially also be used to reverse the mild diastolic dysfunction that occurs in many patients during moderate hypothermia. However, it is too early to recommend the use of this promising drug outside the context of clinical trials.

\section{Abbreviations \\ CO: Cardiac output; DHCA: Deep hypothermic circulatory arrest; ROS: Reactive oxygen species.}

\section{Competing interests}

The author declares that he has no competing interests.

Published: 04 Dec 2013

\section{References}

1. Rungatscher A, Hallström S, Giacomazzi A, Linardi D, Milani E, Tessari M, Luciani GB, Scarabelli T, Mazzucco A, Faggian G: Role of calcium desensitization in the treatment of myocardial dysfunction after deep hypothermic circulatory arrest. Crit Care 2013, 17:R245.

2. Ristagno G, Tantillo S, Sun S, Weil MH, Tang W: Hypothermia improves ventricular myocyte contractility under conditions of normal perfusion and after an interval of ischemia. Resuscitation 2010, 81:898-903.

3. Wold RM, Kondratiev T, Tveita T: Myocardial calcium overload during graded hypothermia and after rewarming in an in vivo rat model. Acta Physiol (Oxf) 2013, 207:460-469.

4. Kondratiev TV, Wold RM, Aasum E, Tveita T: Myocardial mechanical dysfunction and calcium overload following rewarming from experimental hypothermia in vivo. Cryobiology 2008, 56:15-21.

5. Stehle R, Kruger M, Scherer P, Brixius $K$, Schwinger RH, Pfitzer G: Isometric force kinetics upon rapid activation and relaxation of mouse, guinea pig and human heart muscle studied on the subcellular myofibrillar level. Basic Res Cardiol 2002, 97:1127-1135. 
6. Stehle R, lorga B: Kinetics of cardiac sarcomeric processes and ratelimiting steps in contraction and relaxation. J Mol Cell Cardiol 2010, 48:843-850

7. Polderman KH: Mechanisms of action, physiological effects, and complications of hypothermia. Crit Care Med 2009, 37:S186-S202.

8. Polderman KH, Peerdeman SM, Girbes AR: Hypophosphatemia and hypomagnesemia induced by cooling in patients with severe head injury. J Neurosurg 2001, 94:697-705.

9. Polderman KH, Tjong Tjin Joe R, Peerdeman SM, Vandertop WP, Girbes AR: Effects of artificially induced hypothermia on intracranial pressure and outcome in patients with severe traumatic head injury. Intensive Care Med 2002, 28:1563-1567.

10. Aoki M, Nomura F, Stromski ME, Tsuji MK, Fackler JC, Hickey PR, Holtzman DH, Jonas RA: Effects of pH on brain energetics after hypothermic circulatory arrest. Ann Thorac Surg 1993, 55:1093-1103.

11. Churcott CS, Moyes CD, Bressler BH, Baldwin KM, Tibbits GF: Temperature and $\mathrm{pH}$ effects on $\mathrm{Ca} 2+$ sensitivity of cardiac myofibrils: a comparison of trout with mammals. Am J Physiol 1994, 267:R62-R70.

12. Kohlhaas M, Liu T, Knopp A, Zeller T, Ong MF, Bohm M, O'Rourke B, Maack C: Elevated cytosolic $\mathrm{Na}+$ increases mitochondrial formation of reactive oxygen species in failing cardiac myocytes. Circulation 2010 121:1606-1613.

13. Sena $L A$, Chandel NS: Physiological roles of mitochondrial reactive oxygen species. Mol Cell 2012, 48:158-167.

14. Rungatscher $A$, Linardi D, Tessari M, Menon T, Luciani GB, Mazzucco A, Faggian G: Levosimendan is superior to epinephrine in improving myocardial function after cardiopulmonary bypass with deep hypothermic circulatory arrest in rats. J Thorac Cardiovasc Surg 2012, 143:209-214.

15. Lewis ME, Al-Khalidi AH, Townend JN, Coote J, Bonser RS: The effects of hypothermia on human left ventricular contractile function during cardiac surgery. J Am Coll Cardiol 2002, 39:102-108.

$10.1186 / \operatorname{cc} 13139$

Cite this article as: Polderman: Of ions and temperature: the complicated interplay of temperature, fluids, and electrolytes on myocardial function. Critical Care 2013, 17:1018 